\title{
A metaficção na obra de Guel Arraes: uma análise do filme Romance
}

///////////I Afonso Manoel da Silva Barbosa ${ }^{1}$

Luiz Antonio Mousinho Magalhães ${ }^{2}$

1. Graduado em Comunicação Social, com habilitação em Jornalismo, pela Universidade Federal da Paraíba. Mestre em Letras, na área Literatura e Cultura, pela mesma instituição e, atualmente, cursa doutorado em Letras também na UFPB. E-mail: afonso780@yahoo.com.br

2. Possui graduação em Comunicação Social pela Universidade Federal da Paraíba - UFPB (1988), mestrado em Letras pela mesma instituição (1994) e doutorado em Teoria e História Literária pela Universidade Estadual de Campinas - UNICAMP (2003). Atualmente é bolsista de produtividade em pesquisa - $\mathrm{PQ}$, do $\mathrm{CNPq}$ e professor associado II da UFPB. E-mail: lmousinho@yahoo.com.br 
Resumo O presente artigo aborda o filme Romance, de Guel Arraes, investigando suas particularidades metaficcionais. Interessa-nos examinar as peculiaridades estéticas do diretor também a partir de outros de seus trabalhos, como Lisbela e o prisioneiro. Para tanto, nos apoiaremos nos estudos de Robert Stam (2000; 2006); Alexandre Figueirôa e Yvana Fechine (2008); e Gustavo Bernardo (2010).

Palavras-chave Cinema, Guel Arraes, metaficção

Abstract This article discusses the film Romance, by Guel Arraes, investigating its metafictional particularities. We are interested in examining the aesthetic peculiarities from the director along with his other works, such as Lisbela e o prisioneiro. To do so, we will support in the studies of Robert Stam (2000; 2006); Alexandre Figueirôa and Yvana Fechine (2008); and Gustavo Bernardo (2010).

Keywords Cinema, Guel Arraes, metaficcion. 
3. Por ter ouvido escondido e precariamente trechos de uma conversa de Ana, Pedro acredita

que a atriz está mantendo um relacionamento amoroso paralelo. $\mathrm{O}$ ator acredita estar sendo deixado de lado, assim como o teatro, por Ana por conta da TV e de um suposto amante.

\section{Auto-reflexividade: o labor entrevisto}

Romance, de 2008, conta a história de dois atores que se apaixonam durante os ensaios da peça Tristão e Isolda, em São Paulo. Pedro (Wagner Moura) e Ana (Letícia Sabatella) formam esse casal que acaba se separando por conta dos ciúmes 3 dele quando ela recebe um convite para trabalhar na televisão no Rio de Janeiro. Eles se reencontram três anos depois quando Pedro também é convidado pela emissora de Ana para dirigir um especial de TV e sugere uma releitura de Tristão e Isolda ambientada no sertão nordestino do início do século XX.

Guel Arraes investe na construção de narrativas audiovisuais que possuem um substrato metaficcional, realizando trabalhos para a televisão, a exemplo do programa TV pirata, do final da década de oitenta e início da de noventa; e Cena aberta, de 2003. Romance fomenta uma visão da linguagem artística sobre ela mesma e, na representação do real sugerida pelo filme, o labor do processo criativo também compõe a proposta auto-reflexiva. O salto aqui é duplo, pois simboliza, sobretudo, pela forma que Pedro foi moldado enquanto personagem, a representação de uma subjetividade em pleno estágio de laboração artística.

Na diegese, a metaficção reflete e também amplifica essas relações sob a ótica do discurso ficcional. Isso se dá, muitas vezes, pela discussão que se coloca sobre os modos de fazer arte. Elemento que pode ser constatado quando o filme dá forma ao confronto estabelecido entre a liberdade autoral e o lado comercial das produções, ou seja, o dilema entre o artístico e o produto, personificado nas figuras de Pedro (Wagner Moura) e Danilo (José Wilker). 
Observando em Romance esse tipo de construção estética de viés dialógico e metaficcional, é possível ainda assinalar como exemplo a utilização de fragmentos do texto de Tristão e Isolda. O uso desses excertos vai além dos ensaios e das encenações e isso não se restringe apenas às falas, também se consolida a partir das ações realizadas pelo casal de atores. Podemos fazer essa constatação tomando por base a inserção recorrente dos dois bebendo vinho em momentos diferentes da narrativa do filme. A bebida é contextualizada, a princípio, como um elemento importante na história de Tristão e Isolda, sendo apresentada, na peça, como um líquido do amor que provoca paixão naqueles que comungam dele. Fora dos palcos, no restaurante frequentado por eles, Pedro diz que, na tragédia medieval, o vinho servia de pretexto para um sentimento já existente. Fazendo uso da bebida, é com o desdobrar dessa conversa que o casal protagonista do filme começa o relacionamento amoroso.

$\mathrm{O}$ vinho está presente, por exemplo, quando do primeiro beijo do casal, no restaurante, também no reencontro após o rompimento e na reconciliação de Pedro e Ana, no mesmo local. Funciona como leitmotiv, ou seja, como fio condutor de trechos importantes da trama. Segundo Carlos Ceia, o recurso pode ser utilizado "para fazer referência a todos aqueles motivos recorrentes que, no seio de uma narrativa, se encontram intimamente associados a determinadas personagens, objetos, situações ou conceitos abstratos" (CEIA, 2013). A bebida representa esse traço permanente em Romance, onde é demonstrado um processo que dificilmente se dissocia: as relações entre o real diegético e a ficção na narrativa do filme. Tal processo pode ser compreendido a partir das fronteiras que não possuem traços firmes que as definam, como o limite que indica onde a peça - em outras palavras, a representação - começa e a vida ou o relacionamento - a realidade na diegese - dos atores termina.

\section{Metaficção: ludismo e desfaçatez}

Gustavo Bernardo discute o conceito de metaficção, apresentando-a como "um fenômeno estético autorreferente através do qual a ficção duplica-se por dentro, falando de si mesma" (BERNARDO, 2010, p.9). Apesar do uso abundante do recurso em diferentes domínios da arte, como a fotografia, a literatura e o cinema, ainda são poucos os estudos que pautam a temática, pelo menos no Brasil. 


\section{A metaficção na obra de Guel Arraes: uma análise do filme Romance | Afonso Manoel da Silva Barbosa e Luiz Antonio Mousinho Magalhães}

4. Vale destacar que essa expressão, de uso frequente no âmbito dos estudos acadêmicos, é de autoria do poeta e crítico inglês Samuel Taylor Coleridge.

5. Segundo Rosenfeld, "o termo 'verdade', quando usado com referência a obras de arte ou de ficção, tem significado diverso. Designa com frequência qualquer coisa como genuinidade, sinceridade ou autenticidade (...);

ou a verossimilhança, isto é, na

expressão de Aristóteles, não a adequação àquilo que aconteceu, mas àquilo que poderia ter acontecido" (2004, p. 18).
A metaficção, segundo o estudioso, há muito já possuía autores significativos, a exemplo daquilo que fez Miguel de Cervantes em Dom Quixote de La Mancha (BERNARDO, 2010, p.55), e hoje pode ser identificada com mais frequência no campo artístico. Montaigne afirmava que "já se escreveram mais livros sobre outros livros do que sobre qualquer outro assunto" (MONTAIGNE apud STAM, 2000, p.74), o que é visto, inclusive, como uma atividade que cresce bastante na produção literária contemporânea, no ramo da ficção. Um exemplo disso é a reelaboração de um romance a partir de uma perspectiva diferente daquela que o texto base utilizava, tomando, assim, o ponto de vista de personagens secundários ou mesmo imaginários (STAM, 2006, p.31). Como exemplo, podemos destacar a obra Missa do galo: variações sobre o mesmo tema, editado na década de 1970, onde diversos escritores brasileiros reelaboram o famoso conto de Machado de Assis; e Capitu mandou flores, organizado por Rinaldo de Fernandes e publicado em 2008, onde Machado também tem vários de seus contos recontados.

O embate entre quem apregoa à arte a função de espelho do real e aqueles que produzem o desvelamento do fazer artístico no discurso ficcional é um dos elementos analisados por Gustavo Bernardo. O pesquisador ressalta que "os defensores do paradigma realista se incomodam com a metaficção porque ela quebraria o contrato de ilusão entre o autor e o leitor, impedindo a suspensão da descrença $a^{4}$ tão necessária ao prazer da leitura” (2010, p. 40). É necessário compreender que o processo de interlocução é transversal, as relações que o leitor/espectador estabelece com a obra são dinâmicas. Por isso, o prazer da leitura vai estar muito mais ligado a uma lógica poética e interna da obra, que "admite até o impossível, desde que a ele seja concedida uma aura de plausibilidade" (LUNA, 2009, p.42), do que o estabelecimento da quebra desse contrato de ilusão.

Nesse sentido, o discurso metaficcional possui uma certa desfaçatez em relação ao contrato de ilusão por considerar que "a representação de uma coisa nunca será mais do que isso: a representação de uma coisa e não a própria coisa" (BERNARDO, 2010, p. 91). Ao se assumir enquanto produção de sentido, Romance trabalha o conceito de verdade - operacionalizado por Rosenfeld (2004, p.18) - a partir de uma lógica interna - como era preconizado por Aristóteles (LUNA, 2009, p.41-42). Por isso, podemos considerar que 
a ficção não tem a obrigação de dizer a verdade, mas sim a de firmar (ou filmar) uma verdade. $\mathrm{O}$ ato de 'dizer a verdade’ supõe somente uma verdade prévia à ação de expressá-la, enquanto o ato de 'firmar uma verdade' supõe uma verdade possível dentre outras (BERNARDO, 2010, p.182).

Levando para o audiovisual, esse é, certamente, um debate que tem forte ressonância na obra de Guel Arraes. A destituição dos valores de referência daquilo que a televisão comercial convencionalizou é um dos motes da obra do cineasta, apresentando-se como uma proposta sedimentada na forma de antiilusionismo em boa parte de seus trabalhos para a Rede Globo, o que inclusive alimenta a narrativa de Romance.

Dentre suas características “a metaficção é uma ficção que não esconde que o é, mantendo o leitor consciente de estar lendo um relato ficcional, e não um relato da própria verdade" (BERNARDO, 2010, p.42). Apesar de consciente, essa elucidação por parte do interlocutor não se distribui uniformemente como se fosse um bloco maciço, pelo menos quando tomamos como referência tipos distintos de discurso metaficcional. A partir do filme Lisbela e o prisioneiro, percebemos que os pontos "elucidativos" se distribuem de maneira gradual, onde podemos pensar em níveis de desvelamento.

A história narra o encontro de Lisbela (Débora Falabella) e Leléu (Selton Mello). Ela é uma jovem apaixonada por cinema que compara e vê o que acontece ao redor com o olhar contaminado pelos filmes a que assiste. Já ele é um artista saltimbanco que percorre o Nordeste aplicando pequenos golpes e conquistando o coração de inúmeras mulheres por onde passa. Lisbela está de casamento marcado, mas se apaixona por Leléu que acabou de escapar de ser assassinado por se envolver com Inaura (Virgínia Cavendish), uma mulher casada com um matador de aluguel chamado Frederico Evandro (Marco Nanini).

O filme estabelece com o espectador uma espécie de diálogo que perpassa boa parte da trama. Lisbela e o prisioneiro opera também na utilização do cinema enquanto espaço diegético, local que Lisbela antecipa e caracteriza elementos das narrativas a que assiste, como personagens e enredo, e que mantêm um elo com parte da proposta do próprio filme de Guel Arraes. 
A metaficção na obra de Guel Arraes: uma análise do filme Romance | Afonso Manoel da Silva Barbosa e Luiz Antonio Mousinho Magalhães

Esse diálogo, que assume inicialmente um caráter implícito, aos poucos vai sendo explicitado. No final, em contraponto às falas iniciais do filme, que sugerem que o público, ao entrar no cinema, também ingressa paulatinamente em um estado onírico diante do universo paralelo que se estabelece ali, Lisbela prepara o espectador para despertar desse estágio.

Já no caminhão de Leléu, o casal fala sobre a felicidade de estarem juntos. Quando o veículo está para se perder no horizonte, provocando o clássico e codificado happy-ending do cinema americano, Lisbela pede que se pare o caminhão, iniciando assim outra conversa com o seu parceiro de viagem. Léleu, sem entender, questiona o pedido, e Lisbela responde que o melhor do cinema é a forma como o filme acaba, insinuando que os dois devem se beijar. Retomando o desvelamento característico do longa-metragem, ainda de forma sutil, mas direta, nesse momento Leléu passa a falar olhando para a câmera, ao indagar se os dois se beijarão com todo mundo olhando, enquanto Lisbela afirma que isso é só no começo, pois em seguida o filme acaba. A partir daí é dado início, de uma maneira mais aberta, ao diálogo com o público quando Leléu afirma que "então tá bom da gente se apressar porque o povo já entendeu que tá acabando, e é capaz de começar a sair sem prestar mais atenção na gente”.

Diante dessa colocação, Lisbela também responde a Leléu olhando para a câmera, deixando às claras o viés metaficcional do longa-metragem.

É. Mas talvez nessa sala tenha pelo menos um casal apaixonado que vai assistir até o finalzinho. E, mesmo depois do filme acabar, eles vão ficar parados um tempão até o cinema esvaziar todinho. E aí vão se mexendo devagar como se estivessem acordando depois de sonhar com a história da gente.

Antes do último beijo entre os dois, Leléu finaliza dizendo que espera que o público tenha gostado. Por essa construção, o final acaba juntando codificação e vanguarda numa mesma sequência. $\mathrm{Na}$ boleia do caminhão de Leléu, a câmera enquadra os dois personagens em primeiro plano, e quando a tomada passa a ser aberta, o beijo está sendo exibido na tela de uma sala de cinema, 
mais especificamente no mesmo lugar onde o longa-metragem começa. Nesse ambiente, no momento em que estamos vendo o público sair, é dado início à exibição dos créditos de Lisbela e o prisioneiro. Metaforicamente, somam-se, então, essas duas ideias que contribuem para o entendimento de que a obra está sendo concluída. Antes do fim dessa sequência, contudo, é preciso destacar que as últimas pessoas a se levantar e sair da sala são a própria Lisbela e Leléu, o que nos permite resgatar a fala anterior dela quando afirma que ao menos um casal apaixonado assistirá ao filme até o fim. Lisbela e o prisioneiro é, a partir daí, nesse final, a obra dentro da obra.

Claro que as possibilidades de construção do discurso metaficcional são inúmeras. Portanto, esse grau de consciência do leitor/espectador vai depender do tipo de proposta ali apresentada e do seu nível de interação com o objeto artístico, mas trata-se de uma relação que não é uniforme, que varia de obra para obra, da mesma forma que se apresenta como uma experiência diferente para cada interlocutor.

Ainda segundo Gustavo Bernardo, a dinâmica do processo metaficcional se dá em um terreno fértil para a instituição de diálogos. "A conhecida intertextualidade - através da paródia, do pastiche, do eco, da alusão, da citação direta ou do paralelismo estrutural - integra os processos metaficcionais" (2010, p.42-43). Quando tomamos Romance, constatamos parte desses elementos enquanto co-estruturadores da narrativa. Esse princípio dialógico, num viés de leitura bakhtiniano, constitui a auto-reflexividade inerente à obra de Arraes nas representações de Tristão e Isolda, por exemplo. O texto dramático é tratado e retratado a partir de releituras que ressignificam seu espaço narrativo e, por vezes, deslocando até o eixo trágico para o paródico.

\section{TV: naturalismo e anti-ilusionismo}

A confluência de linguagens nas obras de Arraes é característica desde a época em que ele produzia apenas para a televisão e está também presente em seus trabalhos para o cinema, no caso específico, em Romance. A metaficção é um desses artifícios empregados, que parte do desdobramento de uma concepção de Arraes, por ele entender que: 
A metaficção na obra de Guel Arraes: uma análise do filme Romance | Afonso Manoel da Silva Barbosa e Luiz Antonio Mousinho Magalhães

\begin{abstract}
a televisão é o reino do ilusionismo. Toda a promessa da novela, por exemplo, é mostrar as coisas como elas se passam na sua vida. Quando eu cheguei na televisão, observei que havia - e ainda há - um domínio do naturalismo (ARRAES apud FIGUEIRÔA; FECHINE, 2008, p.310).
\end{abstract}

É por esse caminho que o diretor lança mão em seus projetos de uma proposta "antiilusionista", que procura desvendar esse universo da ficção, assumindo, por vezes, uma postura de denúncia como em Romance, mas adotando para isso uma concepção de deboche e brincadeira - fazendo uma união entre o lúdico e o crítico. O discurso de Arraes se propaga de dentro da máquina, mas é sobre a máquina que ele tece muitas de suas críticas. Isso ganha forma, sobretudo, quando analisamos a representação do real por meio da postura de Pedro frente à codificação e às pressões do meio televisivo comercial em nome de uma produção que procure alargar os horizontes estéticos da emissora de Danilo e de seu público.

É importante destacar ainda que, embora a obra de Guel Arraes trabalhe em torno de um viés antiilusionista, é evidente que a recepção tende a cair nas teias da ficção. O que se desdobra, no entanto, é que as propostas utilizam-se de recursos narrativos que investem na comunicabilidade, mas que estão paralelamente ligados a efeitos de sentido que procuram provocar questionamentos no espectador (ARRAES apud FIGUEIRÔA; FECHINE, 2008, p.310).

Em Romance, a utilização de estratagemas que buscam um viés humorístico, e cuja potencialidade responde a uma caracterização paródica, se desenvolvem a partir da codificação explícita das telenovelas em que Ana é protagonista. O filme de Arraes opta por aglutinar os cacoetes de roteiro e de atuação, buscando apresentar ali a tentativa da emissora de sempre trilhar os atalhos para ganhar a audiência mais acostumada aos dramalhões folhetinescos.

Essa mesma faceta não se restringe ao âmbito diegético das novelas em que Ana trabalha. O próprio ambiente de produção, no caso os bastidores das gravações, acaba reunindo também tais indícios que fazem soar essa crítica em forma de paródia. Isso fica claro em várias situações, inclusive quando o diretor de uma das telenovelas tem que gravar finais diferentes na tentativa de manter o suspense do último capítulo e nesses instantes derradeiros pede à produção que 
amarre o elenco ao cenário, validando a ideia do ritmo acelerado no meio televisivo.

Com isso, diante da abrangência e da liberdade que o campo da ficção cinematográfica permite, Arraes procura conduzir seus projetos de forma lúdica, "no uso da metalinguagem fílmica", causando uma "provocação crítica", que é ampliada pelo humor, a partir da "mistura entre o ficcional e o não-ficcional" (ARRAES apud GREGO, 2008, p.236).

Guel Arraes ratifica a tentativa de promover em suas obras o procedimento da linguagem tratando de si mesma, destacando que seus trabalhos possuem certa "preocupação de revelar o ator como um ator, de problematizar o que é real e artificial, verdadeiro ou falso". O diretor acrescenta ainda que, para dar espaço a essa discussão, ele se empenha na utilização da comédia “justamente porque ela é um pouco metalinguística, porque ela debocha dos códigos vigentes. A comédia favorece não só uma crítica de costumes, mas também rupturas de linguagem" (ARRAES apud FIGUEIRÔA; FECHINE, 2008, p.311). Ao desdobrar esse procedimento do diretor em relação ao elemento cômico, podemos nos apoiar naquilo que assinala Linda Hutcheon, quando ela destaca que a paródia, de forma crítica e criativa, popularizou-se como uma estratégia eficaz entre as minorias e segmentos marginalizados para responder a pensamentos dominantes que compõem determinada cultura (HUTCHEON, 1991, p.58). É possível identificar traços que se aproximam dessa linha de raciocínio nos estudos de Robert Stam sobre Bakhtin, quando se coloca que "o artista de uma cultura dominada não pode ignorar a presença estrangeira; é preciso que dialogue com ela, que a engula e a recicle de acordo com objetivos nacionais" (STAM, 2000, p.55), como pode ser identificado nas produções de Guel Arraes, a exemplo do filme Lisbela e o prisioneiro.

Segundo Alexandre Figueirôa, o programa TV Pirata, dirigido por Guel Arraes, "tinha referências calcadas mais em programas de humor da televisão e do teatro besteirol. Era, antes de qualquer coisa, um programa na Globo, parodiando a própria Globo" (2008, p.153). Entre o final da década de 1980 e no início da de 1990, a atração falava de dentro da máquina sobre a própria máquina, seus cacoetes e seus vícios de linguagem. Nesse contexto, "cultiva-se o pastiche, isto é, a imitação de outra obra, com um comportamento 
A metaficção na obra de Guel Arraes: uma análise do filme Romance | Afonso Manoel da Silva Barbosa e Luiz Antonio Mousinho Magalhães

extremamente dessacralizador que oscila entre uma atitude cáustica e uma atitude conformista" (PROENÇA FILHO, 1988, p.41). A trajetória percorrida pelo diretor demonstra a construção de um repertório que se preocupa em evidenciar o fazer artístico metaficcionalmente e unir o crítico ao lúdico num processo que se aproxima às contradições do pós-modernismo: "dentro, porém, fora; cúmplice, porém, crítico” (HUTCHEON, 1991, p.103). Essa relação ambígua perpassa o longa-metragem também por se tratar de uma produção ligada à Rede Globo e que, ao mesmo tempo, critica certos aspectos dos bastidores da televisão comercial. A postura se arquiteta, nesse sentido, por esse viés político paradoxal, contribuindo para a construção de uma crítica que tem a paródia como elemento catalisador na narrativa de Romance.

\section{Prelúdios: elementos metaficionais}

A narrativa de Romance começa concomitantemente à exibição dos créditos iniciais da obra. Pedro, em voz over, lê trechos bastante similares quando tomamos por base O romance de Tristão e Isolda, de Joseph Bédier (2012), dando início ao processo comunicativo proposto pelo filme que se caracteriza como um diálogo introdutório com o público. "Quereis ouvir, senhoras e senhores, um belo conto de amor e de morte? É de Tristão e Isolda, a rainha. Ouvi como em alegria plena e em grande aflição eles amaram, depois morreram no mesmo dia, ele por ela, ela por ele".

Trata-se de um procedimento já utilizado tanto por Guel Arraes quanto por Jorge Furtado (que roteiriza Romance junto a Arraes) no cinema, respectivamente em Lisbela e o prisioneiro e em Saneamento básico, o filme. Temos, como fato comum aos três longas-metragens, uma espécie de prelúdio que consiste em apresentar a obra para o espectador, oferecendo de forma gradual subsídios para a sua iniciação na trama.

No primeiro exemplo, as cenas se passam numa sala de cinema e oferecem um efeito de espelhamento mais específico para aqueles que viram o filme num mesmo tipo de ambiente. Além disso, nesse momento inicial, Lisbela e o prisioneiro investe numa duplicação de caráter auto-reflexivo no sentido de ampliar o registro perceptivo em relação aos personagens que compõem a obra. 
6. E aquela "que nos faz ver o que o personagem vê” (BRITO, 1995, p.209).
Na diegese, conversando com Douglas, logo que sentam no cinema, Lisbela antecipa para ele os acontecimentos da narrativa a que irão assistir. Nessas conjecturas, há um elo existente com o próprio tecido diegético em que ela está inserida. A cada nome de ator que surge na tela - que ela vê e que é a mesma que vemos, como em câmera subjetiva ${ }^{6}$ - Lisbela discorre a respeito de sua função na narrativa. O filme fomenta, desse modo, os processos ficcionais num diálogo estabelecido com o público e que percorre boa parte do longa-metragem.

Quando analisamos Saneamento básico, de Furtado, a voz over de Marina é utilizada ainda na exibição dos créditos iniciais e procura passar para o espectador a ideia de que ela está organizando um grupo de pessoas que está prestes a assistir a um filme. Mais à frente, no prosseguimento da narrativa, vemos tratar-se, na verdade, de uma reunião de moradores com o intuito de discutir os problemas de saneamento que a comunidade está enfrentando.

O artifício em Saneamento básico também trabalha em nome de uma auto-referencialidade que tende a instigar no espectador uma inserção progressiva no estágio onírico que o cinema proporciona. Trata-se de um indício preliminar da concepção metaficcional que é proposta pelas obras e seu uso produz o estreitamento entre o público e a noção de descortinamento do ficcional que elas produzem.

No prefácio de O romance de Tristão e Isolda, Joseph Bédier alerta para a dificuldade de definir a matriz da lenda que deu origem à história. "Se eu fosse indicar minhas fontes pormenorizadamente, teria de encher os rodapés das páginas deste livrinho de tantas notas" (BÉDIER, 2012, p.XVI). Ele revela, entretanto, no prosseguimento dessa advertência, uma série de referências utilizadas e adaptadas que vão desde trechos de poemas a fragmentos anônimos para a construção da versão que ele concebe.

O argumento básico da trama se desdobra com a ideia do sobrinho que vai buscar a mulher que será desposada pelo tio e se apaixona por ela. A questão do destino, dos mal-entendidos e do "amor recíproco infeliz" trabalha essa engrenagem trágica da história, fazendo com que "o espírito que a anima do começo ao fim, que circula em todos os seus episódios, como o 'beber amoroso' nas veias dos dois heróis [seja] a ideia da fatalidade do amor, que o eleva acima de todas as leis" (PARIS, 2012, p. XIII). 


\section{A metaficção na obra de Guel Arraes: uma análise do filme Romance | Afonso Manoel da Silva Barbosa e Luiz Antonio Mousinho Magalhães}

Podemos refletir a respeito dos diálogos implícitos e explícitos estabelecidos com o público nos filmes de Arraes e Furtado, observando que esse procedimento tem sido bastante utilizado em produções artísticas a partir de diversos tipos de discurso ficcional ao redor do mundo. Foi esteticamente bem aproveitado por Machado de Assis, em obras como Dom Casmurro, que foi adaptada para a Rede Globo, em 2008, no formato minissérie e intitulada Capitu, preservando ainda essa proposta de viés comunicativo e auto-reflexivo.

Essa possibilidade narrativa também figura na obra de Joseph Bédier, que aqui trago como alicerce para analisar Romance. Já nas primeiras frases de O romance de Tristão e Isolda e no desenvolvimento do livro, o artifício aparece constantemente e ganha forma em trechos como o que segue:

\footnotetext{
Senhores, o contador que quer agradar deve evitar as histórias demasiado longas. A matéria deste conto é tão bela e tão diversa: de que serviria alongá-lo? Direi pois, de modo breve, como, após ter vagado durante muito tempo por mares e países, Rohalt, o Defensor da Fé, aportou nas Cornualhas, reencontrou Tristão (BÉDIER, 2012, p.7).
}

No caso específico de Romance, as reelaborações de Tristão e Isolda fazem trabalhar esse dínamo que transforma um arcabouço de referências em um debate acerca do fazer artístico, da liberdade autoral e dos limites da arte. Se é que estes existem. Melhor que a ideia de limite, a obra investe nas fronteiras entre campos discursivos distintos, como TV, cinema e teatro, por exemplo, na pressão que Pedro sofre para escrever um final feliz, modificando o fim trágico, para o especial que vai ao ar na emissora.

Podemos inferir que, por estabelecer uma ponte entre o experimental e o convencional, unindo continuidade e ruptura e apresentando feições características do pós-modernismo, as obras de Guel Arraes, como ele próprio assinala, podem ser analisadas a partir da ideia de que elas partem de "uma posição de mais equilíbrio, nem num extremo nem no outro; estamos sempre em cima do muro, somos equilibristas mesmo e não à toa que, muitas vezes, ou somos elogiados ou tomamos porrada dos dois lados" (ARRAES apud FIGUEIRÔA; FECHINE, 2008, p.311). 
Do ponto de vista dialógico, a partir da função de diretor de núcleo exercida por Guel Arraes, houve a possibilidade de reunir "artistas e criadores, vindos das mais diversas áreas - cinema, teatro, jornalismo, e da própria televisão -, o que vai ser fundamental para configurar uma das características de seus produtos audiovisuais, que é o hibridismo de linguagens" (FIGUEIRÔA, 2008, p.153). Esse imbricamento de fontes discursivas, além das relações constantes entre enunciados e a parceria com subjetividades diversas ajudaram o diretor na elaboração de produções plurais no nível de sua significação.

Os laços, empréstimos e transversalidades entre texto e contexto, emissor e receptor, estão presentes na obra de Guel Arraes e, por meio dela, são trabalhados diegeticamente produzindo uma representação do real que valoriza o labor artístico. Sua construção, seus meios de reprodução e os diálogos com outras obras constituem o processo comunicativo que opera no cerne da metaficção. 
A metaficção na obra de Guel Arraes: uma análise do filme Romance | Afonso Manoel da Silva Barbosa e Luiz Antonio Mousinho Magalhães

\section{Referências}

BÉDIER, J. O romance de Tristão e Isolda. Tradução: Luis Claudio de Castro Costa. São Paulo: WMF Martins Fontes, 2012.

BERNARDO, G. O livro da metaficção. Rio de Janeiro: Tinta Negra Bazar Editorial, 2010.

BRITO, J. B. de. Imagens amadas: ensaios de crítica e teoria do cinema. São Paulo: Ateliê Editorial, 1995.

CALLADO, A. et al. Missa do galo: variações sobre o mesmo tema. Rio de Janeiro: José Olympio, 2008.

CEIA, C. E-Dicionário de termos literários. Disponível em: $\quad<$ http://www.edtl.com.pt/index.php?option=com_ mtree\&task=viewlink\&link_id=895\&Itemid=2>. Acesso em: 27 jan. 2014.

FERNANDES, R. Capitu mandou flores. São Paulo: Geração editorial, 2008.

FIGUEIRÔA, A.; FECHINE, Y. (Org.). Guel Arraes: um inventor no audiovisual brasileiro. Recife: Companhia Editora de Pernambuco, 2008.

FIGUEIRÔA, A. Uma via de mão dupla: cinema e televisão na obra de Guel Arraes. In: FIGUEIRÔA, A.; FECHINE, Y. (Org.). Guel Arraes: um inventor no audiovisual brasileiro. Recife: Companhia Editora de Pernambuco, 2008.

GREGO, A. Rastros de um processo de criação: o caso Lisbela e o Prisioneiro. In: FIGUEIRÔA, A.; FECHINE, Y. (Org.). Guel Arraes: um inventor no audiovisual brasileiro. Recife: Companhia Editora de Pernambuco, 2008.

HUTCHEON, L. Poética do pós-modernismo: história, teoria, ficção. Rio de Janeiro: Imago, 1991. 
LUNA, S. Dramaturgia e Cinema: ação e adaptação nos trilhos de Um Bonde Chamado Desejo. João Pessoa: Ideia, 2009.

PARIS, G. Prefácio. In: BÉDIER, J. O romance de Tristão e Isolda. Tradução: Luis Claudio de Castro Costa. São Paulo: WMF Martins Fontes, 2012.

PROENÇA FILHO, D. Pós-modernismo e literatura. São Paulo: Ática, 1988.

ROSENFELD, A. Literatura e personagem. In: CANDIDO, A. (Org.). A personagem de ficção. São Paulo: Perspectiva, 2004.

STAM, R. Bakhtin - da teoria literária à cultura de massa. São Paulo: Ática, 2000.

- Teoria e prática da adaptação: da fidelidade à intertextualidade. In: CORSEUIL, A. R. (ed.). Ilha do desterro: Film Beyond Boundaries. Florianópolis, UFSC, n 51, Jul/Dez 2006.

Artigo recebido em março e aprovado em junho de 2014. 